\title{
Using the Regional Ocean Modeling System (ROMS) to improve the ocean circulation from a GCM $20^{\text {th }}$ century simulation
}

\author{
Arne Melsom • Vidar Suren Lien • \\ William Paul Budgell
}

Received: 4 March 2009 / Accepted: 30 July 2009 / Published online: 3 September 2009

(C) The Author(s) 2009. This article is published with open access at Springerlink.com

\begin{abstract}
Global coupled climate models are generally capable of reproducing the observed trends in the globally averaged atmospheric temperature. However, the global models do not perform as well on regional scales. Here, we present results from a 20-year, high-resolution ocean model experiment for the Atlantic and Arctic Oceans. The atmospheric forcing is taken from the final 20 years of a twentieth-century control run with a coupled atmosphere-ocean general circulation model. The ocean model results from the regional ocean model are validated using observations of hydrography from repeat cruises in the Barents Sea. Validation is performed for average quantities and for probability distributions in space and time. The validation results reveal that, though the regional model is forced by a coupled global model that has a noticeable sea ice bias in the Barents Sea, the hydrography and its variability are reproduced with an encouraging quality. We attribute this improvement to the realistic transport of warm, salty waters into
\end{abstract}

Responsible Editor: Phil Dyke

A. Melsom ( $\varangle)$

Norwegian Meteorological Institute,

P.O. Box 43 Blindern, 0313 Oslo, Norway

e-mail: arne.melsom@met.no

V. S. Lien · W. P. Budgell

Institute of Marine Research, Bergen, Norway

W. P. Budgell

Bjerknes Centre for Climate Research, Bergen, Norway

W. P. Budgell

Dept. of Physics and Physical Oceanography,

Memorial University of Newfoundland,

St. John's, Newfoundland and Labrador, Canada the Barents Sea in the regional model. These lateral fluxes in the ocean are severely underestimated by the global model. The added value with the regional model that we have documented here lends hope to advance the quality of oceanic climate change impact studies.

Keywords Model validation - Barents Sea • Regional climate $\cdot$ Ocean modeling

\section{Introduction}

Climate and climate change affect the Barents Sea ecosystem by influencing species through changes in reproduction, recruitment (Sætersdal and Loeng 1987; Ellertsen et al. 1989), growth, and distribution (Nakken and Raknes 1987; Michalsen et al. 1998). Therefore, marine ecosystems are vulnerable to climate change, especially when key species are affected. In order to address the implications of future climate change on assessments of marine resources, results are needed with a resolution that resolves the relevant physical quantities, such as eddies and a realistic description of the bottom topography and the coastline. However, a horizontal resolution of the order of a few kilometers, which is needed for such purposes, is still not feasible when running global climate models.

The Barents Sea is a major heat sink for the Atlantic water on its way to the Arctic Ocean. Water mass transformation through freezing of sea ice and subsequent brine release and cooling of the ocean produces dense water that may sink to great depths in the Arctic Ocean (Midttun 1985). This contributes to the deep water formation in the Arctic (e.g., Rudels et al. 1994; Schauer et al. 2002; Quadfasel et al. 1988) and, thus, also to 
the Atlantic thermohaline circulation. In order to get a realistic Barents Sea climate, it is therefore important to get a sufficient inflow of warm Atlantic water into the Barents Sea with a subsequent cooling of this water mass.

While model results for the northern hemisphere sea ice edge generally agree reasonably well with observations, Arzel et al. (2006) find that over half of the atmosphere-ocean general circulation models (AOGCMs) used in the fourth assessment report from the Intergovernmental Panel on Climate Change (IPCC-4AR) overestimate sea ice in the southern Barents Sea. Arzel et al. (2006) also note that models that perform well when validating the present climate sea ice extent are not necessarily also superior when it comes to results for the poleward heat transport. According to Parkinson et al. (2006), the oceanic heat transport by the North Atlantic Current in the Nordic Seas is underestimated in several of the IPCC-4AR climate models. This often leads to excessive sea ice cover in the Barents Sea region in the models. Moreover, the coarse resolution of these models makes it impossible to represent the topographic features with which the currents that transport heat into the Barents Sea are associated.

Here, we try to overcome some of these problems by applying atmospheric forcing from the atmospheric module of an AOGCM to a basin-scale, highresolution, coupled ocean/sea ice model. Thus, some important processes that are not resolved or included in the coarser climate models are described in the highresolution regional model. These differences include a more realistic bathymetry, shelf-ocean interactions, tides, and improved mixing. Our model will reproduce the Atlantic inflow to the Nordic Seas (Sand $\varnothing$ and Furevik 2008), as well as to the Barents Sea, as long as the large-scale wind stress curl over the Atlantic and Nordic Seas is captured. The higher-resolution ocean model can then properly represent the roles of topography, tidal mixing, and fronts to produce a realistic ocean circulation. A similar effort has previously been performed for another shelf area, the North Sea (Ådlandsvik and Bentsen 2007).

Most evaluations of the performance of climate models in the Arctic have focused on atmosphere properties (e.g., Chapman and Walsh 2007; Walsh et al. 2008) and the seasonal variability and/or trends of sea ice extent (e.g., Parkinson et al. 2006; Arzel et al. 2006; Overland and Wang 2007). Regional sea ice/ocean circulation models for the Arctic forced with atmospheric reanalysis products have also been examined (e.g., Karcher et al. 2003; Maslowski et al. 2004). Walsh et al. (2008) compute the multi-model area-mean root-mean-square error (RMSE) of the surface temperature of the atmosphere. They find that the RMSE is in the range 3-6 K for the various seasons, when the region northward of $60^{\circ} \mathrm{N}$ is considered. Chapman and Walsh (2007) report negative biases during winter in the Barents Sea of $8-12 \mathrm{~K}$ in their examination of 14 IPCC-AR4 AOGCMs. In order to examine the relations between such relatively large errors in the atmospheric module of coupled climate models with the corresponding ocean circulation in the Arctic, we force a regional ocean/sea ice circulation model with atmosphere results from an AOGCM. The distribution of oceanic heat and salt in the problematic region of the Barents Sea are validated using various techniques, including a novel examination of how well the inter-annual variability is reproduced. Results for a 15-year present climate period are evaluated in this study, and we find that the results are substantially improved when compared to the corresponding results from the global model.

The aim of this paper is to validate the regional model for the Barents Sea and quantify the added value relative to a global simulation. Section 2 presents the AOGCM that is considered, and describes the highresolution ocean/sea ice model from which results will be analyzed here. Then, the data sets used in the validation are described in Section 3. A brief introduction to the general hydrography and circulation at the entrance to the Barents Sea is given in Section 4. The validation follows in Section 5, and some conclusions are presented at the end of the paper in Section 6.

\section{The model experiment}

From the International Panel on Climate Change Fourth Assessment Report (IPCC WG-I/8 et al. 2007b), results from 20 AOGCMs are available. Ideally, all AOGCMs should be used in making an ensemble of regional simulations. However, due to both feasibility and the quality of the results of global AOGCMs on regional scales, results from only one AOGCM are used to force the regional ocean/sea ice model. In this study, a good representation of sea ice in the Arctic in general and the Barents Sea in particular is rated as the most important criterion when choosing an AOGCM. Overland and Wang (2007) use a limit of reproducing Arctic ice area within $20 \%$ and seasonal ice zone within $30 \%$ of observations as criteria for classifying a model as "good" in the present context. Then, out of the 20 AOGCMs, only three models perform well in both the Arctic as a whole and in the Barents Sea. In the present study, the Goddard Institute for Space Studies Atmosphere-Ocean Model (GISS AOM) is 
chosen. The other two models passing the two "goodness" criteria in both the Arctic and the Barents Sea are Community Climate System Model version 3.0 of the National Center for Atmospheric Research and the Hadley Centre Global Environmental Model version 1 of the Hadley Centre for Climate Prediction and Research.

GISS AOM ran on a global grid with a resolution of four by three degrees in longitude and latitude, respectively, in both the atmosphere and the ocean. Geo-potential was used as the coordinate in the vertical direction in the ocean module, with a maximum of $16 z$ levels. The number of vertical layers in the ocean depends on the horizontal location but is constant in time. The layer thicknesses are adjusted at each horizontal location after computation by the dynamical subroutines at each time step such that the ratio of the mass of a grid box divided by the mass of the grid box below it is $8 / 11$. A sea ice model calculating sea ice thickness and snow amount was coupled to the model system. Tides were not included. See the GISS AOM website http://aom.giss.nasa.gov/ for further details.

The coupled ice-ocean numerical model used for the regional simulation is the Regional Ocean Modeling System (ROMS), described in Shchepetkin and McWilliams (2005). The regional model is run on a stretched orthogonal curvilinear grid with an average resolution of $10 \mathrm{~km}$, covering the Arctic and the Atlantic down to about $20^{\circ} \mathrm{S}$. The domain and the variable resolution is displayed in Fig. 1. In the vertical, 40 generalized sigma (s-coordinate) levels are applied using the scheme of Song and Haidvogel (1994), with stretching that enhances the resolution towards the surface and the bottom. This provides a very good vertical resolution in shelf areas. For example, with a depth of $200 \mathrm{~m}$ and the parameter for surface stretching $\theta_{s}=5.0$, the parameter for bottom stretching $\theta_{b}=0.4$, and a critical depth of $10 \mathrm{~m}$, at a pycnocline depth of about $20 \mathrm{~m}$, the vertical grid resolution is better than $3.7 \mathrm{~m}$. The method for computing the horizontal pressure gradient has been described by Shchepetkin and McWilliams (2003).

Daily mean sea level pressure, surface winds, surface air temperatures, surface specific humidity, downward long wave radiation at the surface, downward short wave radiation at the surface, and precipitation values were extracted from the GISS AOM results and used to provide atmospheric forcing for ROMS through the use of the bulk flux algorithm due to Fairall et al. (2003). At the lateral open boundaries of the ocean module, monthly mean climatological values from the Simple Ocean Data Assimilation (SODA) data set (Carton et al. 2000a, b) for the period 1981-2000 are used. Ice
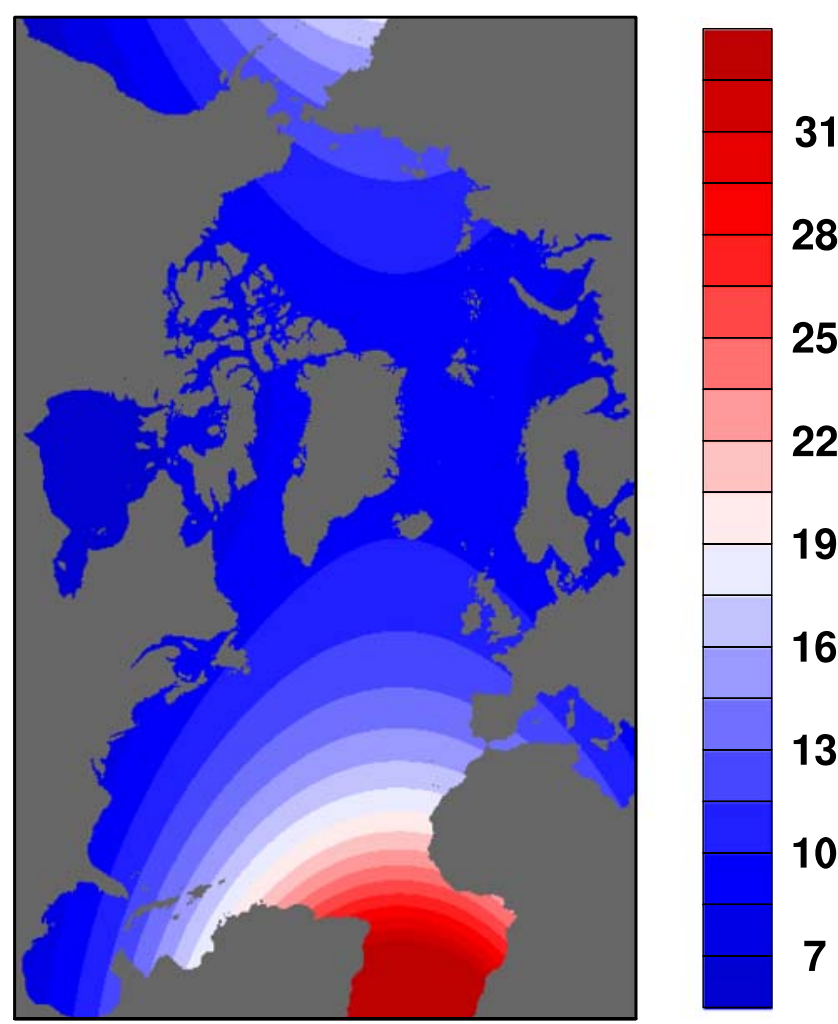

Fig. 1 Model domain and horizontal resolution. Land (dry grid cells) are displayed as gray regions, while the color shading corresponds to resolution in $\mathrm{km}$ as given by the color bar to the right. A contouring interval of $1.5 \mathrm{~km}$ was used

concentration, thickness, and velocity lateral boundary conditions for the sea ice module were taken from an annual monthly mean climatology constructed from GISS AOM fields for the period 1981-2000. Initial conditions were taken from January values from the SODA and GISS AOM climatologies for ocean and ice variables, respectively. Along the open boundary in the South Atlantic, SODA has a horizontal resolution of $50-55 \mathrm{~km}$, while the corresponding resolution in GISS AOM is about $350 \mathrm{~km}$.

Tides are included in the ROMS simulation, with eight tidal constituents (M2, S2, N2, K2, K1, O1, P1, and Q1) from TPX 0.7 (Egbert and Erofeeva 2002) and tidal potential. Preliminary validation of model results with current meter data in the Barents Sea region suggests that modelled tidal current amplitudes are approximately $10 \%$ too large (G. Forristal, personal communication). The tides are important for mixing and ice freezing/melting in the Barents Sea and, thus, important for the heat transfer from ocean to atmosphere. In a numerical sensitivity study covering the Barents Sea, Harms et al. (2005) found an annual average of $15 \%$ increase in heat loss from ocean to atmosphere by 
including M2 tide compared to a control run without tides.

The ice model dynamics are based on the elasticviscous-plastic (EVP) rheology after Hunke and Dukowicz (1997) and Hunke (2001), and the ice thermodynamics are based on Mellor and Kantha (1989) and Häkkinen and Mellor (1992). The ice module used in ROMS has been ported from the Norwegian Meteorological Institute's Ice Model (MI-IM), documented by Røed and Debernard (2004).

The Barents Sea includes areas that are seasonally or permanently ice-covered. Atmosphere-ocean fluxes therefore have a large spatial and temporal variability. There is no coupling back from the regional model to the atmospheric boundary layer. However, feedback between the model surface temperature and the computed sensible, latent, and net long-wave radiation heat fluxes reduces the problem with drift in the surface temperature in ROMS. Still, wrong ice distribution in the climate model will affect the atmosphere-ocean fluxes in the high-resolution model. This is a major challenge.

To prevent long-term drift in the model salinity, the sea surface salinity is restored to climatology based on the Common Ocean-Ice Reference Experiment (CORE; see http://data1.gfdl.noaa.gov/nomads/ forms/mom4/COREv2.html) (Large and Yeager 2008), with a restoration time of 360 days. Although restoring the sea surface salinity towards climatology, this allows for some inter-annual variability in the model salinity. Together with the flux correction, this reduces the regional model sensitivity to regional biases in the climate model atmosphere.

Surface freshwater runoff forcing was also obtained from CORE. The data are the annual mean river runoff distributed globally with a resolution of $1^{\circ}$ in longitude and latitude. The data were interpolated to the model grid and took the same form as precipitation input, i.e., the freshwater supply altered the surface salt flux but no mass or momentum was added to the system. Hence, the diffuse nature of this runoff forcing does not allow for the evolution of coastal currents and salinity fronts at a distance of the order of $100 \mathrm{~km}$ off the coastline, even though the resolution in ROMS is sufficiently fine to describe such currents. Additional errors result from the lack of an annual cycle in the river runoff forcing.

The ROMS simulations have been performed for two periods, 1981-2000 representing the present climate and 2046-2065 representing the future scenario SRES A1B (IPCC WG-I/2 et al. 2007a). Five years is considered as spin-up, and only the remaining 15 years are used in the analysis. The first period will be used as a control run and is validated in this work, while analysis of results for the latter period will be reported in an upcoming publication.

\section{Observations and model results}

Hydrographic data along fixed cruise tracks and cast positions are available from the Institute of Marine Research (IMR; Kangas et al. 2006). The data have been subjected to a quality assurance process at IMR, using the The Integrated Global Ocean Services System standard. Observations were made as CTD casts with a vertical resolution ranging from 1 to $5 \mathrm{~m}$. Here, the data were integrated over $10-\mathrm{m}$ bins prior to the model validation. There are three cruise tracks that are frequently visited, from which the data are relevant for the present purpose. These tracks are "Bjørnøya west" (BW), "Fugløya-Bjørnøya" (FB), and "Vardø north" (VN). The number of CTD casts from these cruise tracks that are used in the present analysis is listed in Table 1. The cruise tracks and positions of the CTD casts are displayed in Fig. 2.

The results from GISS AOM are available as monthly means. Results were provided on a variable resolution grid in the vertical, consisting of 31 geopotential levels. As described in Section 2, the spatial resolution in GISS AOM is $4^{\circ}$ in longitude, $3^{\circ}$ in latitude. As can be seen from Fig. 2, each of the cruise tracks is spanned by very few grid cells in the GISS AOM (two to four cells). Hence, examination of horizontal gradients along the cruise tracks is of little value. Note also that a point-to-point comparison along the FB track will be tainted by the the poor local representation of the Norwegian coast in this region.

The present ROMS simulation uses variable resolution in the horizontal. As shown in Fig. 1, the resolution in the Barents Sea region is $8-9 \mathrm{~km}$. Results from ROMS were available at the $40 s$ levels used in the simulation.

For the validation in Section 5, all model results are interpolated linearly in time. In the vertical direction, results are extracted from the model layer that corresponds to the observation depth. When a model's

Table 1 Hydrographic data used in the present study

\begin{tabular}{lcccc}
\hline Cruise track & Winter & Spring & Summer & Fall \\
\hline Bjørnøya west & 0 & 86 & 84 & 127 \\
Fugløya-Bjørnøya & 308 & 579 & 447 & 448 \\
Vardø north & 286 & 233 & 393 & 212 \\
\hline
\end{tabular}

Values are no. CTD casts from the three cruise tracks from the period 1986-2000, sorted by season. Winter, spring, summer, and fall are defined as D-J-F, M-A-M, J-J-A, and S-O-N, respectively 


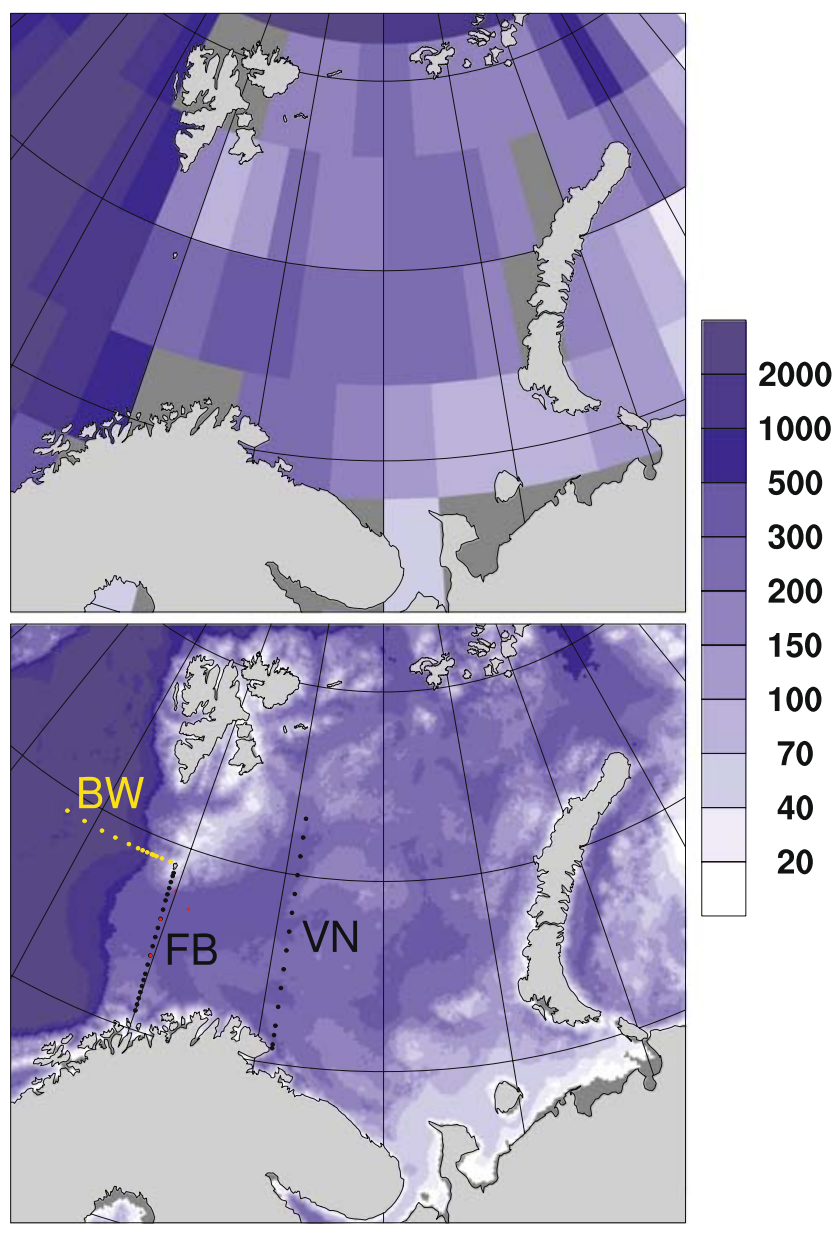

Fig. 2 The bottom topography in GISS AOM and ROMS for the Barents Sea region is displayed in the top and bottom panels, respectively. Grid cells that are dry are shown as dark gray regions. Actual land has been superimposed as light gray regions. The shading corresponds to model depth in $\mathrm{m}$, as given by the color bar to the right. Full circles show the positions of the CTD stations where the observations were taken, along the labelled cruise tracks "Bjørnøya west" $(B W)$, "Fugløya-Bjørnøya" $(F B)$, and "Vard $\varnothing$ north" $(V N)$. Red dots indicate the positions of the moorings that are used in Section 5.3. Note that two of the mooring sites coincide with stations of the "Fugløya-Bjørnøya" cruise track

bottom depth is smaller than the observed bottom depth, the deepest model value is extrapolated downward. In the horizontal, bi-linear interpolation is applied.

The seasonal variability has a considerable magnitude in the present region, both in the atmosphere and in the upper ocean. Moreover, while sea ice has only rarely occurred in the tracks in recent years, more than half of the coupled ocean-atmosphere models have a seasonal ice cover in the entire Barents Sea in their baseline climate (1980-1999) (IPCC WG-I/8 et al. 2007b). Hence, we will conduct the present analysis on a seasonal basis. Here, we define the seasons as winter in December, January, and February, spring in March, April, and May, summer in June, July, and August, and fall in September, October, and November. Note that there were very few casts available from the BW track during winter, so hydrographic data and model results from BW for this season are discarded in the present analysis.

\section{The regional ocean circulation and hydrography}

The mean values for salinity and temperature from the upper $50 \mathrm{~m}$ reveal that all of the three tracks are dominated by water masses that are relatively saline and warm for such high latitudes. The main source is the poleward-flowing Norwegian Atlantic Current, which splits into two branches as it leaves the coast of northern Norway.

The western branch continues northward along the continental shelf break and becomes the West Spitsbergen Current. The BW cruise track intersects this current. The eastern branch flows eastward into the Barents Sea as the North Cape Current. This current is first intersected by the FB track, and further to the east by the VN track.

Coastal water in the Norwegian Coastal Current (NCC), occupying the southernmost part of the FB track, accounts for an additional volume and heat transport into the Barents Sea. This water mass is distinguishable from Atlantic water by its lower salinity range $(S<34.7)$. A common definition of Atlantic water in the Barents Sea is by temperature $\left(T>3{ }^{\circ} C\right)$ and salinity $S>35.0$ (Loeng 1991). Based on an array of moorings along the FB track and using these criteria, Skagseth et al. (2008) found that this branch carries $1.8 \mathrm{~Sv}$ of Atlantic water on average, with a corresponding heat flux of $48 \mathrm{TW}$. The inflow was reported to show an upward trend of 0.1 Sv/year from 1997 to 2006 and a relatively large temporal variability on several time scales.

The data show that the saltiest water is found in the BW track, reaching an average value of 34.99 in the upper $50 \mathrm{~m}$ of the cross-section during spring. The corresponding maxima for the $\mathrm{FB}$ and $\mathrm{VN}$ tracks are 34.88 and 34.83 , respectively. There is a general freshening in the upper $50 \mathrm{~m}$ as the water flows eastward from FB to $\mathrm{VN}$, ranging from 0.01 during fall to 0.09 during spring.

The coldest cross-sectional average of the upper ocean water is found in $\mathrm{BW}$, which is the northernmost track. Here, the average temperature reaches a high of $5.3{ }^{\circ} \mathrm{C}$ during summer. In $\mathrm{FB}$ and $\mathrm{VN}$, the seasonal highs are attained during fall, with values of $7.1^{\circ} \mathrm{C}$ and 
$6.3{ }^{\circ} \mathrm{C}$, respectively. There is a cooling in all seasons of the upper ocean as the water flows eastward in the southern part of the Barents Sea. The largest cooling from $\mathrm{FB}$ to $\mathrm{VN}$ is $1.3 \mathrm{~K}$, which occurs during winter when the overlying atmosphere is at its coldest.

\section{Model validation}

The model validation is performed by comparing model results that are interpolated in space and time to the observed data, as outlined in Section 3. It is important to realize that the atmospheric forcing in this region has considerable variability, which, to a large extent, is associated with the North Atlantic Oscillation (NAO; Hurrell 1995; Hurrell et al. 2003). NAO is due to processes that are internal to the atmosphere (Thompson et al. 2003) and has a random and unpredictable character on time scales ranging from months to decades (Hurrell et al. 2003). The GISS AOM simulation does not include assimilation of observations; hence, the local atmospheric circulation in GISS AOM from a particular month and year will generally correspond to a NAO signal that is different from the observed index value at that time. The validation that follows in Subsections 5.1-5.3 is restricted to the upper $50 \mathrm{~m}$ of the water column, which is significantly impacted by the ocean-atmosphere fluxes. In order to account for the discrepancy regarding NAO, we compare observations with model results at the corresponding time of the year, but the actual year is chosen randomly from the 15 years with available model results from ROMS.

Most of the NAO variability occurs at time scales less than 3 years (see, e.g., Fig. 12 in Hurrell et al. 2003). Hence, statistical measures such as biases and probability distributions that are derived from a 15-year analysis are representative, since errors that are associated with mismatching conditions and different NAO indices will tend to cancel each other. Even the temporal variability itself can be validated by examining the scatter in time in the observations and model results.

There is an underlying trend in the global atmospheric surface temperature for the period in question due to trends in the composition of Earth's atmosphere (IPCC WG-I/2 et al. 2007a). Changes in the radiative forcing are included in the coupled GISS AOM simulation, which this study is based upon. However, the amplitude of the regional internal atmospheric variability in the Arctic is of a much larger magnitude than the global trends (Räisänen 2002).

Due to the poor match between the horizontal resolution in GISS AOM and the distance between the positions of the CTD stations, we will limit the validation of results from GISS AOM to integrated statistics (mean bias) for the BW track (which represents the water masses in the Nordic Seas adjacent to the Barents Sea) and VN track (the longest of the cruise tracks). Validation of integrated quantities (fluxes of mass and heat) from GISS AOM is also provided.

\subsection{Overall validation}

The biases of the model results with respect to the observations are listed in Table 2. We note that, in the upper $50 \mathrm{~m}$, ROMS is somewhat warmer than the observations in the west (BW and FB), and generally slightly too salty in the east (FB and VN). Overall, the ROMS results are remarkably close to the observations. GISS AOM is too cold (by about $1 \mathrm{~K}$ ) and too fresh (by 0.2-0.3) when compared to data from the BW track. Moreover, the validation of GISS AOM exhibits a significant deterioration inside the Barents Sea, with biases of $5 \mathrm{~K}$ and 1 in temperature and salinity, respectively.

In order to gain more insight into the performance of ROMS, we compute the probability density function (pdf) for temperature and salinity in the upper $50 \mathrm{~m}$,
Table 2 Biases in hydrography results relative to the observations

Results for the upper $50 \mathrm{~m}$ for temperature (in $\mathrm{K}$ ) and salinity are shown in the upper and lower half of the table, respectively

\begin{tabular}{|c|c|c|c|c|c|}
\hline Cruise track & Model & Winter & Spring & Summer & Fall \\
\hline \multicolumn{6}{|l|}{ Temperature } \\
\hline Bjørnøya west & GISS AOM & & -1.0 & -1.1 & -0.5 \\
\hline Vardø north & GISS AOM & -4.2 & -4.2 & -5.3 & -4.3 \\
\hline Bjørnøya west & ROMS & & 0.3 & 0.1 & 0.2 \\
\hline Fugløya-Bjørnøya & ROMS & 0.6 & 0.6 & 0.2 & -0.2 \\
\hline Vardø north & ROMS & -0.0 & -0.5 & -0.8 & -1.0 \\
\hline \multicolumn{6}{|l|}{ Salinity } \\
\hline Bjørnøya west & GISS AOM & & -0.26 & -0.27 & -0.19 \\
\hline Vard $\varnothing$ north & GISS AOM & -0.79 & -0.76 & -1.33 & -1.43 \\
\hline Bjørnøya west & ROMS & & -0.04 & -0.02 & 0.10 \\
\hline Fugløya-Bjørnøya & ROMS & -0.04 & 0.04 & 0.12 & 0.18 \\
\hline Vard $\varnothing$ north & ROMS & 0.06 & 0.05 & 0.15 & 0.20 \\
\hline
\end{tabular}




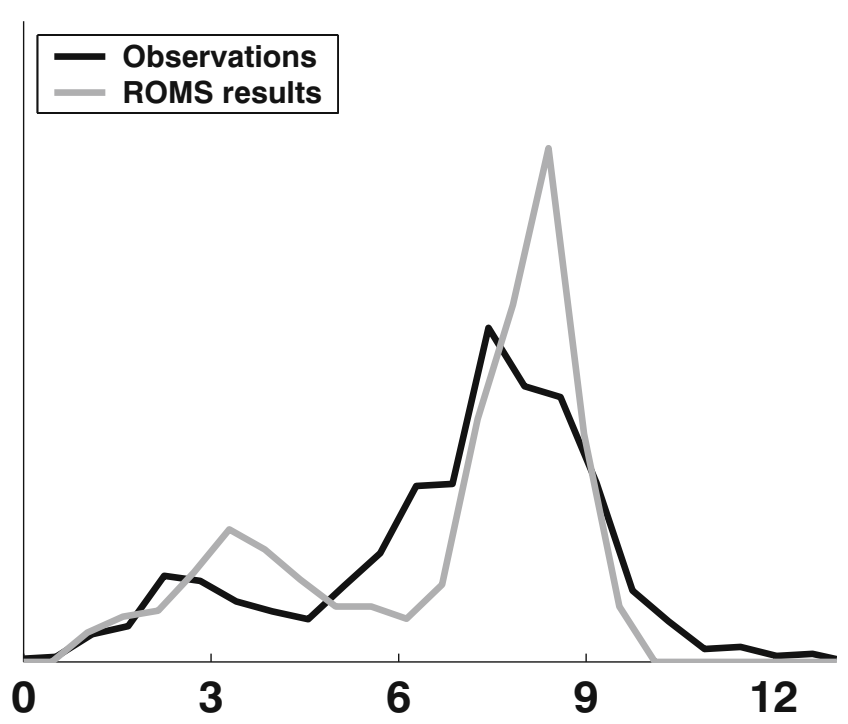

Fig. 3 Probability density function for temperature for the fall (S-O-N) season from the "Fugløya-Bjørnøya" track. The analysis was restricted to observations and model results from the upper $50 \mathrm{~m}$. Values along the horizontal axis are temperatures in ${ }^{\circ} \mathrm{C}$. The amplitude has been scaled so that the area under each curve is the same

based on observations and model results from the fall season. The results for temperature and salinity from the FB track are shown in Figs. 3 and 4, respectively.

With the exception of the higher peak, the pdfs for temperature are similar in most aspects. The skewness parameter is -0.72 and -0.90 for observations and ROMS, respectively. The pdfs for temperature from the VN track are similar to those from the FB track.

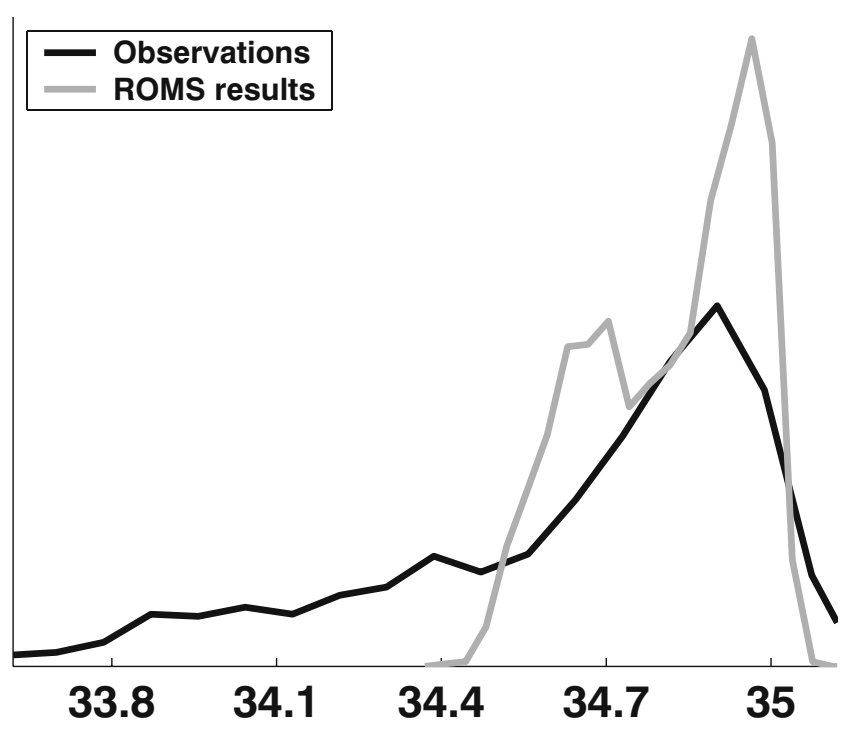

Fig. 4 Same as Fig. 3, but for salinity
The pdf from the ROMS results for salinity is also similar to the observed distribution in most aspects.

The most striking misrepresentation is that salinity values that are smaller than 34.4 are absent in the model. These results are representative for all seasons from the FB track. The lack of water masses in the model that have the signature of a coastal current is a primary cause for the narrower distributions and higher peaks in the pdfs of ROMS results. This discrepancy is due to the use of a $1^{\circ}$ product for the runoff forcing.

The pdfs provide valuable information about the overall variability in the sampled region. However, they give no information about how the variability is distributed in space and time.

\subsection{Variability in space}

The cross-sectional averages of temperature and salinity in the FB track for the fall season are displayed in Figs. 5 and 6, respectively. Model results were interpolated to the observations' positions prior to averaging.

Again, we find that the results from ROMS are strikingly similar to the observations, particularly for temperature. There are horizontal fronts in the ROMS results that are in the correct positions when compared to the observed fronts; the ROMS salinity fronts are too weak, though. Observations and ROMS results for other seasons exhibit similar features to those from the fall season.

The results for the BW track (not shown) are similar to those from FB, with a temperature front near Bjørnøya in the observations and in the results from ROMS. For the VN track (also not shown), there are no well-defined temperature fronts in the cross-sectionally averaged fields, although the observations and the ROMS results are somewhat colder in the north. The salinities from ROMS are close to the observed values in the interior, but ROMS underestimates the gradient near the coast, as it does not reproduce the magnitude of the salinity minimum in this region. This is due to the coarse resolution of the freshwater runoff forcing from the CORE data set, as discussed in Section 2.

In order to assess the magnitude of the differences between model results and observations, it is useful to scale these differences by a spatially dependent quantity that represents variability. Here, we compute the standard deviation of temperature and salinity for each season, from each CTD station and each $10 \mathrm{~m}$ bin in the vertical, based on all of the observations available from 1980 to 2007.

The absolute values of the normalized model vs observation differences are then computed, and results are weighted spatially by the distance between the 


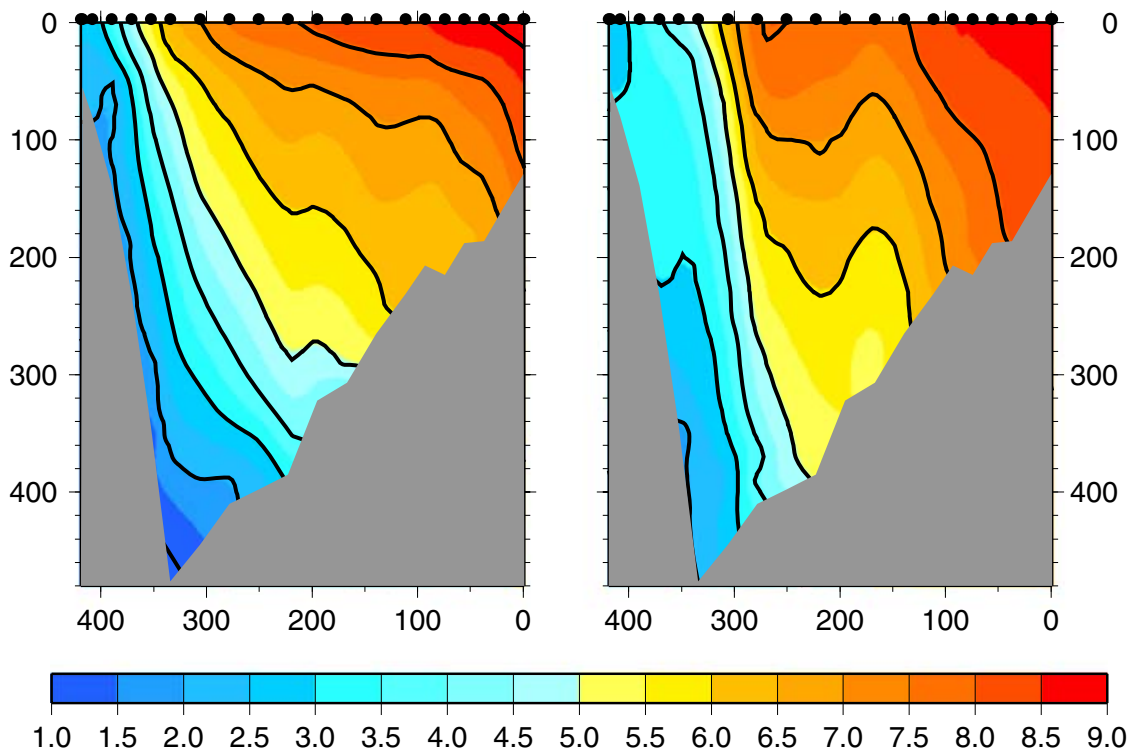

Fig. 5 Temperature cross-section of the "Fugløya-Bjørnøya" cruise track, based on all dates in the fall season (S-O-N) with cruise data for the period 1986-2000. Results based on observations and the ROMS model are displayed to the left and right, respectively. The shading corresponds to temperature values as given in ${ }^{\circ} \mathrm{C}$ by the color bar at the bottom, and contour lines

various CTD stations. The resulting mean normalized differences are listed in Table 3. Note that results from GISS AOM are not given, due to its insufficient horizontal resolution for the present purpose.

As explained above, there is no inter-annual phase lock between model results and observations. Hence, any mean normalized difference significantly smaller than 1 should be treated with suspicion. However, since have been added for each $1^{\circ}$ value. The vertical axes annotation values are depths in $\mathrm{m}$, while values along the horizontal axes are distances from the southernmost CTD station, in $\mathrm{km}$. The positions of the stations are shown as full black circles at the top of each panel, and the figures are drawn to view the cross-section from west towards east

the validation is performed with monthly means from the models, and instantaneous measurements, even a "perfect" model will have a normalized difference that is not 1 . Presently, the normalization is carried out based on the observed variability, which has a higher variability than that from monthly mean values. Thus, we expect normalized differences to be somewhat lower than 1 for a "perfect" model. From Table 3, we
Fig. 6 Same as Fig. 5, but for salinity

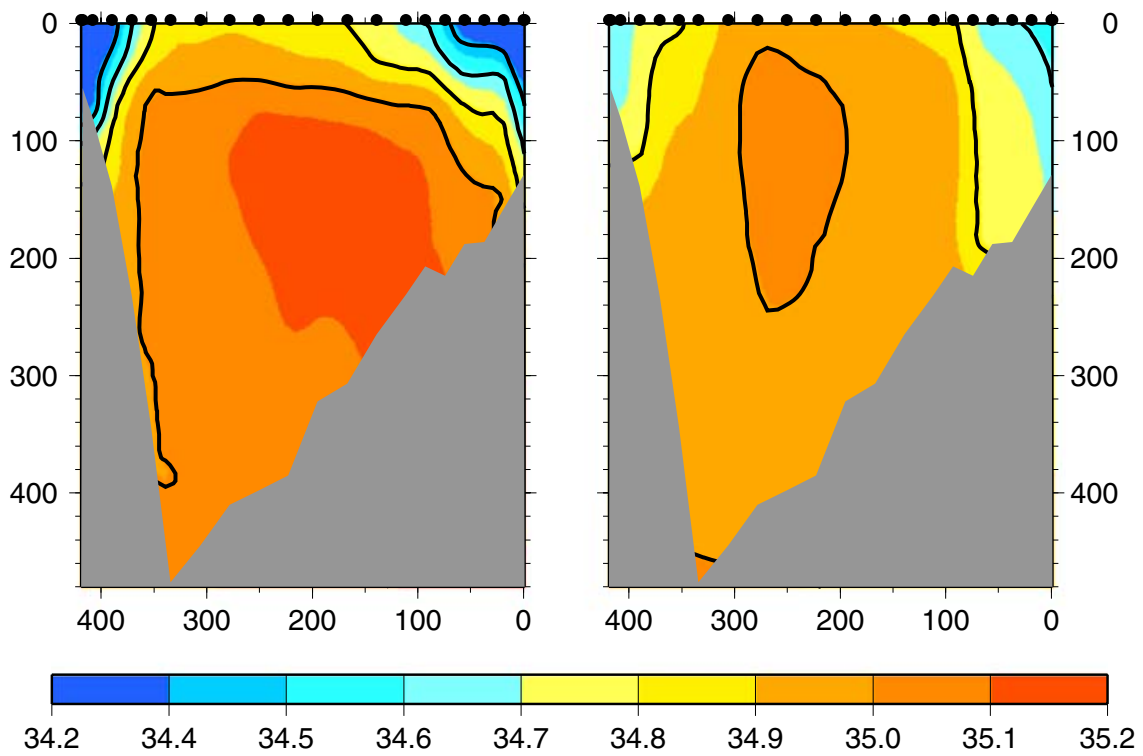


Table 3 Normalized model vs observation differences for hydrography

\begin{tabular}{|c|c|c|c|c|c|}
\hline Cruise track & Model & Winter & Spring & Summer & Fall \\
\hline \multicolumn{6}{|l|}{ Temperature } \\
\hline Bjørnøya west & ROMS & & 1.0 & 0.8 & 0.9 \\
\hline Fugløya-Bjørnøya & ROMS & 1.0 & 1.3 & 0.8 & 0.9 \\
\hline Vard $\varnothing$ north & ROMS & 0.8 & 1.3 & 0.7 & 1.1 \\
\hline \multicolumn{6}{|l|}{ Salinity } \\
\hline Bjørnøya west & ROMS & & 1.4 & 1.3 & 1.8 \\
\hline Fugløya-Bjørnøya & ROMS & 1.4 & 1.4 & 1.0 & 1.0 \\
\hline Vard $\varnothing$ north & ROMS & 1.3 & 1.0 & 1.1 & 0.9 \\
\hline
\end{tabular}

Results for the upper $50 \mathrm{~m}$ for temperature (in $\mathrm{K}$ ) and salinity are shown in the upper and lower halves of the table, respectively

see that, with one exception, the normalized ROMS model vs observation differences are in the range 0.7-1.4.

\subsection{Variability in time}

As discussed above, it is difficult to assess the normalized model vs observation differences due to the lack of an optimal result. In order to shed more light on this topic, we propose to take advantage of the fact that the inter-annual variability in the observations and model results are de-coupled. Then, we can examine how well the observed temporal variability is described by the model by applying the method of ranking that is used for validation of an ensemble (Hammill 2001). Based on the mean temperature from ROMS in the upper $50 \mathrm{~m}$ of the FB track, we find that the auto-correlation at lags of 1 and 2 years are 0.4 and -0.3 , respectively. Hence, we set the de-correlation time scale to 2 years and can construct an eight-member ensemble of the results for 1986-2000.

Another topic that needs to be addressed in this context is the mismatch in the sampling from the model and instruments. Model results are available as monthly means, whereas observations from the CTD casts are instantaneous. An analogous issue in the analysis of ensembles in weather forecasting is that, in order to correctly analyze the ensemble, one needs to take errors in the instrumental records into account. This can be done by adding noise to the observations to mimic instrument errors (Saetra et al. 2004).

In the present case, the mismatch introduced by monthly averaging of model results is much greater than the instrument errors. We have four time series of continuous temperature observations in the vicinity of the FB track at our disposal, their locations are displayed as red dots in Fig. 2. From two of the moorings, no data were available at depths smaller than $50 \mathrm{~m}$. As an estimate of the variance that is lost by application of a monthly average, we compute the root mean square (RMS) offset from a least squares fit to each month of data from all moorings, at the 50-m level. We find that, during spring, the RMS offsets range from 0.1 to $0.4 \mathrm{~K}$, while the corresponding range from the fall season is 0.1 to $0.55 \mathrm{~K}$. For both seasons, the RMS differences increase from south to north. In the analysis that follows, we have thus added Gaussian noise with standard deviation given by the RMS values after the model results for each year were found by interpolating linearly in time between the monthly averages.

If the statistical properties of the inter-annual variability in the observations and the model results are the same, the probability that the observed value is smaller than the ensemble minimum, between the ensemble minimum and the second smallest ensemble value, etc., is the same for each interval (Hammill 2001). In an eight-member ensemble, there are nine different possible outcomes of such a ranking. Here, we simplify by restricting the analysis to count the frequency of observations that are inside the range of the ensemble. This corresponds to seven of the nine intervals, so ideally, the frequency should be $7 / 9=0.78$.

The aim here is to validate variability in time. However, the representation of spatial scales will also have an effect on ranking. If fronts such as those displayed in, e.g., the left panel of Fig. 5 are not resolved in the model, ranking will show that the model underestimates variability even if the temporal variability is described correctly. Hence, due to the coarse horizontal resolution in GISS AOM, we will limit the ranking analysis to the results from ROMS.

The results from the analysis for the FB track are provided as Table 4, for the low and high estimates of the RMS offsets in the data from the moored instruments. The probability of observed values falling inside either ensemble range is lower than the optimal value of 0.78 , for both seasons and the whole RMS range.

Table 4 Fraction of temperature observations from the FugløyaBjørnøya track that falls within the ensemble range based on results from ROMS, based on observations at levels in the range $40-50 \mathrm{~m}$

\begin{tabular}{llll}
\hline Season & RMS & Raw & De-biased \\
\hline Spring & 0.10 & 0.43 & 0.51 \\
& 0.40 & 0.56 & 0.58 \\
Fall & 0.10 & 0.52 & 0.55 \\
& 0.55 & 0.70 & 0.72 \\
\hline
\end{tabular}

The optimal value for a eight-member ensemble is 0.78 . RMS temperature offsets are in K. De-biasing was performed by subtracting the average of differences between model results and observations for levels between 40 and $50 \mathrm{~m}$ from the entire FB track. See the text for additional details 
Nevertheless, given the slight underestimation of spatial variability that is evident from Fig. 5, we find that the temperatures from ROMS give a reasonable representation of the observed variability. A crude measure of the model performance in this context is "variability percentage," as given by the fraction between the tabulated values and the optimal value (0.78). Using the debiased model results, the percentage from the average of the low and high RMS estimates becomes $70 \%$ and $81 \%$ for spring and fall, respectively.

\subsection{Volume and heat fluxes}

It is difficult to make a consistent comparison between observed and modeled volume and heat fluxes. Observations are based on point measurements, while model data provide area averages over a grid box, but with higher spatial resolution than the observations. The distance between observation points is larger than the eddy scale, which would influence the comparison between model and observations even for a "perfect" model. Bias and possible drift in modeled salinity often complicate the comparison further, by obscuring the water mass definitions that are appropriate for the analysis of model results.

Figures 4 and 6 show that the salinity in the ROMS results is biased. They also show that water masses such as coastal water are underestimated in the model, seen by the lack of a tail at the lower end in the salinity pdf (Fig. 4). Two different approaches to separate Atlantic water from coastal water in the model include using temperature only and restrict the analysis to the geographical extent of the moorings, or using both temperature and salinity adjusted for model bias. In this validation, the first method is applied. This is consistent with the observations by Ingvaldsen et al. (2004), and will effectively distinguish between water masses of Atlantic origin and water masses in the NCC, as the $\mathrm{NCC}$ is situated south of the mooring section. The latter method, however, gave only slightly different results. In GISS AOM, the criterion is applied on the whole opening between Norway and Svalbard.

For the period 1986-2000, the modeled net inflow to the Barents Sea is 2.4 Sv in GISS AOM and 2.1 Sv in ROMS for all water masses. Using the definition above gives a corresponding Atlantic inflow of $1.1 \mathrm{~Sv}$ in GISS $\mathrm{AOM}$ and $1.8 \mathrm{~Sv}$ in ROMS. The observations reported by Skagseth et al. (2008) give an average Atlantic inflow of $1.8 \mathrm{~Sv}$. The different results from the two models are mainly due to too-low temperatures in GISS AOM, as shown in Fig. 5.

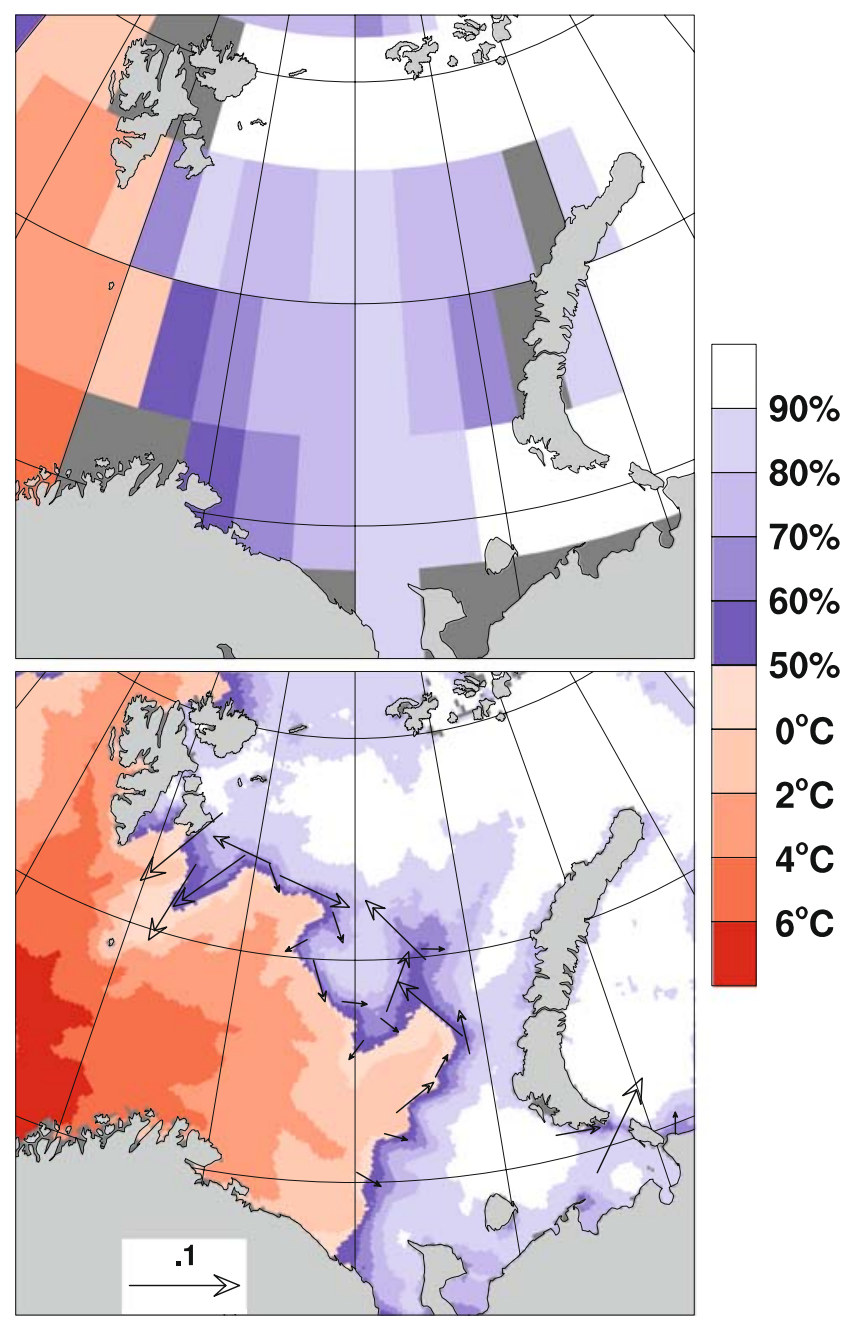

Fig. 7 Mean ice concentration and sea surface temperature (SST) in the Barents Sea during May, based on results from GISS AOM (top) and ROMS (bottom). The shading corresponds to ice cover area fractions wherever this exceeds $50 \%$ and SST values elsewhere, as given by the color bar to the right. Vectors display the velocity of sea ice in regions where the concentration is in the range $50-70 \%$. The lengths of the vectors have been scaled by the caption arrow inside the white box in the bottom panel, which corresponds to a speed of $0.1 \mathrm{~m} / \mathrm{s}$. Vectors are only displayed when the speed is larger than $0.02 \mathrm{~m} / \mathrm{s}$. This threshold was not exceeded anywhere in the GISS AOM results for this region

In winter/spring, no water masses are classified as Atlantic water in GISS AOM, resulting in zero inflow of Atlantic water in the months February through May. The net inflow of all water masses, however, only shows a slight decline throughout winter and spring, and varies between 2.1 Sv in June and 2.9 Sv in October. The heat flux reflects the low temperatures and varies between $13 \mathrm{TW}$ in March (0 TW for Atlantic water) and $45 \mathrm{TW}$ in October (42 TW for Atlantic water), with an average of $27 \mathrm{TW}$ (16 TW for Atlantic water) for 
the whole period 1986-2000. This agrees poorly with observations (Skagseth et al. 2008), which suggest that the average heat flux carried by the Atlantic water into the Barents Sea is $48 \mathrm{TW}$. The heat flux is greatly increased in ROMS, despite a reduction in the total volume flux. For the whole period, the average net heat flux from all water masses amounts to $65 \mathrm{TW}$ in the ROMS simulation, while the Atlantic water contributes with 46 TW.

Further, Skagseth et al. (2008) find that variability in heat flux through FB track is dominated by fluctuations in volume transport rather than temperature fluctuations: They found a higher heat flux in winter, when temperatures are lower, and attributed this to the stronger volume transports in winter.

GISS AOM shows the opposite behavior, with temperature changes being the dominant factor for the variability of heat flux in the inflow to the Barents Sea. The extensive Barents Sea ice cover in winter in GISS AOM (see Fig. 7 for the results from May) is attributed to the low heat flux into the Barents Sea in winter.

Although the ROMS results agree very well with observations regarding average fluxes on decadal timescales, the temporal variability is too low in the model. Skagseth et al. (2008) found the 12-month running mean volume transport into the Barents Sea to vary between a minimum of $0.8 \mathrm{~Sv}$ and maximum of $2.9 \mathrm{~Sv}$ within the 10-year period 1997-2006 (see Table 5 here). For the heat flux, the minimum and maximum values were 29 and 70 TW, respectively. The corresponding values from the 15-year period with results from ROMS are 1.5 and $2.1 \mathrm{~Sv}$ for volume transport minimum and maximum, respectively, and 41 and 51 TW for heat transport minimum and maximum, respectively.

Table 5 Volume fluxes (in Sv) and heat fluxes (in TW) through Barents Sea opening for Atlantic water only (defined geographically, see text)

\begin{tabular}{lccc}
\hline Source & Mean & Min & Max \\
\hline Volume flux & & & \\
GISS AOM & 1.1 & 0.6 & 1.5 \\
ROMS & 1.8 & 1.5 & 2.1 \\
Observations & 1.8 & 0.8 & 2.9 \\
Heat flux & & & \\
GISS AOM & 16 & 8 & 25 \\
ROMS & 46 & 41 & 51 \\
Observations & 48 & 29 & 70 \\
\hline
\end{tabular}

Min and max values are minimum and maximum values in 12month filtered time series
GISS AOM shows a larger relative variability than the ROMS results, but the average fluxes are substantially underestimated, as described above. As also revealed by Table 5, ROMS produces realistic inflow of both volume and heat into the Barents Sea.

\section{Conclusion}

In the ROMS simulation that is examined here, ROMS was coupled to a dynamic-thermodynamic sea ice model as described in Budgell (2005). The results for sea ice from the GISS AOM and ROMS experiments are connected to the ocean temperature results as expected, since the Barents Sea has a much larger ice cover in the colder GISS AOM. We particularly observe that the sea ice retreat in GISS AOM is delayed in the spring season, as can be seen from Fig. 7. The GISS AOM results for sea ice, where the Barents Sea is, e.g., almost completely ice-covered during winter, does not at all correspond to the observations. The sea ice results can be compared to the observations from 1990 that are displayed in Rayner et al. (2003), see, e.g., their Fig. 1c,d. While the ROMS results also display a too-extensive sea ice cover, it is much closer to the observations than the GISS AOM ice cover.

The excess heat carried into the Barents Sea by Atlantic water in ROMS, as compared to GISS AOM, has an average value of $30 \mathrm{TW}$ (see Table 5), or $8 \cdot 10^{19} \mathrm{~J}$ per month. If all of this energy is consumed by ice melting, this corresponds to a 1-m-thick ice cover over the entire Barents Sea being melted during a period of 4 months. We also note from Fig. 7 that ice retreat in ROMS due to advection only has an impact locally. Advection of sea ice in GISS AOM is slowpaced everywhere in the Barents Sea. Hence, most of the improvement in the description of sea ice in ROMS can be attributed to its realistic heat transport.

The same atmospheric forcing is applied to both of the ocean and sea ice models, albeit in different ways, since GISS AOM is a fully coupled system. Obviously, one must expect that the ROMS results are at least somewhat tainted by the GISS AOM atmosphere that has a lower boundary that is much too cold. Hence, it is encouraging to find that, even under these conditions, ROMS can provide results that constitute a realistic description of the hydrographic conditions in the upper water masses of the Barents Sea.

We have demonstrated that a regional ocean circulation model, run with a much higher horizontal resolution than what is feasible with a coupled general circulation model, is capable of a realistic representation of the 
ocean circulation in a shelf sea. However, it is important to realize that the impact of the large-scale circulation may differ from one shelf sea to another. The Barents Sea is characterized by a strong impact from relatively warm waters that enter in the west, making it a much warmer shelf sea with less sea ice than other shelf seas at similar latitudes.

This study gives us reason to believe that much value can be added to projections of the future ocean climate from coupled AOGCMs by down-scaling using regional modeling. While AOGCMs that are eddy resolving in the ocean are not likely to transpire in the foreseeable future, regional models can provide information with a resolution that is more relevant for, e.g., oceanic biota.

The present results are generated on a variable mesh grid that is sufficient for resolving important large-scale circulation features such as the Gulf Stream separation (Smith et al. 2000), but too coarse to reproduce the circulation on the scales at which most meso-scale activity is found at high latitudes. Hence, extending the methodology by nesting an even smaller domain into a regionally downscaled model may be useful from the viewpoint of climate change impact studies.

\begin{abstract}
Acknowledgements This work has been supported by the Climate of Norway and the Arctic in the 21st Century (NorClim) and Norwegian Ecosystem Studies of Sub-Arctic Seas (NESSAS) projects and the NOTUR supercomputing project, which are financed by the Research Council of Norway. GISS AOM results were downloaded from IPCC AR4 data archive at Lawrence Livermore National Laboratory. Computations were performed on the Atlantic Computational Excellence Network (ACEnet) of Canada facilities. Figures 1, 2, and 7 were made using NCAR Command Language (NCL; http://ncl.ucar.edu).
\end{abstract}

Open Access This article is distributed under the terms of the Creative Commons Attribution Noncommercial License which permits any noncommercial use, distribution, and reproduction in any medium, provided the original author(s) and source are credited.

\section{References}

Arzel O, Fichefet T, Goosse H (2006) Sea ice evolution over the 20th and 21st centuries as simulated by current AOGCMs. Ocean Model 12:401-415. doi:10.1016/j.ocemod.2005.08.002

Ådlandsvik B, Bentsen M (2007) Downscaling a 20th century global climate simulation to the North Sea. Ocean Dyn 57:453-466

Budgell WP (2005) Numerical simulation of ice-ocean variability in the Barents Sea region: towards dynamical downscaling. Ocean Dyn 55:370-387. doi:10.1007/s10236-005-0008-3

Carton JA, Chepurin G, Cao X, Giese BS (2000a) A Simple Ocean Data Assimilation analysis of the global upper ocean 1950-1995, part 1: methodology. J Phys Oceanogr 30: 294-309
Carton JA, Chepurin G, Cao X (2000b) A Simple Ocean Data Assimilation analysis of the global upper ocean 1950-1995, part 2: results. J Phys Oceanogr 30:311-326

Chapman WL, Walsh JE (2007) Simulations of Arctic temperature and pressure by global coupled models. J Climate 20:609-632. doi:10.1175/JCLI4026.1

Egbert GD, Erofeeva SY (2002) Efficient inverse modeling of barotropic ocean tides. J Atmos Ocean Technol 19:183-204

Ellertsen B, Fossum P, Solemdal P, Sundby S (1989) Relations between temperature and survival of eggs and first feeding larvae of the North-East Arctic cod (Gadus morhua L.). Rapports et Procs-verbaux des Runions du Conseil international pour lExploration de la Mer 191:209-219

Fairall CW, Bradley EF, Hare JE, Grachev AA, Edson JB (2003) Bulk parameterization of air-sea fluxes: updates and verification for the COARE algorithm. J Climate 16:571-591

Häkkinen S, Mellor GL (1992) Modelling the seasonal variability of a coupled arctic ice-ocean system. J Geophys Res 97:20285-20304

Hammill TM (2001) Interpretation of rank histograms for verifying ensemble forecasts. Mon Weather Rev 129:550-560

Harms IH, Schrum C, Hatten K (2005) Numerical sensitivity studies on the variability of climate-relevant processes in the Barents Sea. J Geophys Res 110:C06002. doi:10.1029/ 2004JC002559

Hunke E, Dukowicz J (1997) An elastic-viscous-plastic model for sea ice dynamics. J Phys Oceanogr 27:1849-1867

Hunke E (2001) Viscous-plastic sea ice dynamics with the EVP model: linearization issues. J Comput Phys 170:18-38

Hurrell JW (1995) Decadal trends in the North Atlantic Oscillation and relationships to regional temperature and precipitation. Science 269:676-679

Hurrel JW, Kushnir Y, Ottersen G, Visbek M (2003) An overview of the North Atlantic oscillation. In: Hurrell JW, Kushnir Y, Ottersen G, Visbeck M (eds) The North Atlantic Oscillation: climate significance and environmental impact. Geophysical Monograph Series, vol 134. Amer. Geophys. Union, pp 1-35

Ingvaldsen RB, Asplin L, Loeng H (2004) The seasonal cycle in the Atlantic transport to the Barents Sea during the years 1997-2001. Cont Shelf Res 24:1015-1032

IPCC WG-I/2, Trenberth KE, Jones PD, Ambenje P, Bojariu R, Easterling D, Tank AK, Parker D, Rahimzadeh F, Renwick JA, Rusticucci M, Soden B, Zhai P (2007a) Observations: surface and atmospheric climate change. In: Solomon S, Qin D, Manning M, Chen Z, Marquis M, Averyt KB, Tignor M, Miller HL (eds) Climate change 2007: the physical science basis. Contribution of working group I to the fourth assessment report of the intergovernmental panel on climate change. Cambridge University Press, Cambridge

IPCC WG-I/8, Randall DA, Wood RA, Bony S, Colman R, Fichefet T, Fyfe J, Kattsov V, Pitman A, Shukla J, Srinivasan J, Stouffer RJ, Sumi A, Taylor KE (2007b) Climate models and their evaluation. In: Solomon S, Qin D, Manning M, Chen Z, Marquis M, Averyt KB, Tignor M, Miller HL (eds) Climate change 2007: the physical science basis. Contribution of working group I to the fourth assessment report of the intergovernmental panel on climate change. Cambridge University Press, Cambridge

Kangas T-V, Svendsen E, Strand $\varnothing$ (2006) Average value of salinity and temperature in the Institute of Marine Research's fixed sections (in Norwegian). Report series "Fisken og Havet" 6/2006. Institute of Marine Research, Bergen, $53 \mathrm{pp}$

Karcher MJ, Gerdes R, Kauker F, Köberle (2003) Arctic warming: evolution and spreading of the 1990 s warm event in the 
Nordic seas and the Arctic Ocean. J Geophys Res 108:3034. doi:10.1029/2001JC001265

Large WG, Yeager SG (2008) The global climatology of an interannually varying airsea flux data set. Clim Dyn 33:341-364. doi:10.1007/s00382-008-0441-3

Loeng H (1991) Features of the physical oceanographic conditions of the Barents Sea. Pol Res 10:5-18

Maslowski W, Marble D, Walczowski W, Schauer U, Clement JL, Semtner AJ (2004) On climatological mass, heat, and salt transports through the Barents Sea and Fram Strait from a pan-Arctic coupled ice-ocean model simulation. J Geophys Res 109:C03032. doi: 10.1029/2001JC001039

Mellor GL, Kantha L (1989) An ice-ocean coupled model. J Geophys Res 94:10937-10954

Michalsen K, Ottersen G, Nakken O (1998) Growth of Northeast Arctic cod (Gadus morhua L.) in relation to ambient temperature. ICES J Mar Sci 55:863-877

Midttun L (1985) Formation of dense bottom water in the Barents Sea. Deep Sea Res A 32:1233-1241

Nakken O, Raknes A (1987) The distribution and growth of Northeast Arctic cod in relation to bottom temperatures in the Barents Sea, 1978-1984. Fish Res 5:243-252

Overland JE, Wang M (2007) Future regional Arctic sea ice declines. Geophys Res Lett 34:L17705 doi:10.1029/ 2007GL030808

Parkinson CL, Vinnikov KY, Cavalieri DJ (2006) Evaluation of the simulation of annual cycle of Arctic and Antarctic sea ice coverages by 11 major global climate models. J Geophys Res 111:C07012. doi:10.1029/2005JC003408

Quadfasel D, Rudels B, Kurz K (1988) Outflow of dense water from a Svalbard fjord into the Fram Strait. Deep Sea Res A 35:1143-1150

Räisänen J (2002) $\mathrm{CO}_{2}$-induced changes in interannual temperature and precipitation variability in 19 CMIP2 experiments. J Climate 15:2395-2411

Rayner NA, Parker DE, Horton EB, Folland CK, Alexander LV, Rowell DP, Kent EC, Kaplan A (2003) Global analyses of sea surface temperature, sea ice, and night marine air temperature since the late nineteenth century. J Geophys Res 108(D14):4407. doi:10.1029/2002JD002670

Røed LP, Debernard J (2004) Description of an integrated flux and sea-ice model suitable for coupling to an ocean and atmosphere model. met.no Report 4/2004. Norwegian Meteorological Institute, Oslo, 56 pp. http://met.no/filestore/MI-IM-Documentation.pdf

Rudels B, Jones EP, Anderson LG, Kattner G (1994) On the intermediate depth waters of the Arctic Ocean. In:
Johannessen OM, Muench RD, Overland JE (eds) The polar oceans and their role in shaping the global environment. Geophysical Monograph Series, vol 84. AGU, Washington, DC, pp 33-46

Sand $\varnothing$ AB, Furevik T (2008) Relation between the wind stress curl in the North Atlantic and the Atlantic inflow to the Nordic Seas. J Geophys Res-Oceans 113. doi:10.1029/ 2007JC004236

Schauer U, Loeng H, Rudels B, Ozhigin VK, Dieck W (2002) Atlantic water inflow through the Barents and Kara Seas. Deep Sea Res I 49:2281-2298

Sætersdal G, Loeng H (1987) Ecological adaption of reproduction in Northeast Arctic cod. Fish Res 5:253-270

Saetra $\varnothing$, Hersbach H, Bidlot J-R, Richardson DS (2004) Effects of observation errors on the statistics for ensemble spread and reliability. Mon Weather Rev 132:1487-1501

Shchepetkin AF, McWilliams JC (2003) A method for computing horizontal pressure-gradient force in an oceanic model with a non-aligned vertical coordinate. J Geophys Res 108:1-34

Shchepetkin AF, McWilliams JC (2005) The Regional Ocean Modeling System (ROMS): a split-explicit, free-surface, topography-following coordinates ocean model. Ocean Model 9:347-404

Skagseth $\varnothing$, Furevik T, Ingvaldsen R, Loeng H, Mork KA, Orvik KA, Ozhigin V (2008) Volume and heat transports to the Arctic via the Norwegian and Barents Seas. In: Dickson R, Meincke J, Rhines P (eds) Arctic-subarctic ocean fluxes. Defining the role of the northern seas in climate. Springer, Netherlands. doi:10.1007/978-1-4020-6774-7

Smith RD, Maltrud ME, Bryan, FO, Hecht MW (2000) Numerical simulation of the North Atlantic Ocean at $\frac{1}{10}^{\circ}$. J Phys Oceanogr 30:1532-1561

Song Y, Haidvogel, DB (1994) A semi-implicit ocean circulation model using a generalized topography-following coordinate system. J Comp Phys 115(1):228-244

Thompson DWJ, Lee S, Baldwin MP (2003) Atmospheric processes governing the Northern Hemisphere Annular Mode/North Atlantic Oscillation. In: Hurrell JW, Kushnir Y, Ottersen G, Visbeck M (eds) The North Atlantic Oscillation: climate significance and environmental impact. Geophysical Monograph Series, vol 134. American Geophysical Union, Washington, DC, pp 81-112

Walsh JE, Chapman WL, Romanovsky V, Christensen JH, Stendel M (2008) Global climate model performance over Alaska and Greenland. J Climate 21:6156-6174. doi:10.1175/ 2008JCLI163.1 